\title{
Making a better case for biodiversity conservation: the BESAFE project
}

\author{
Rob Bugter ${ }^{1} \cdot$ Paula Harrison $^{2} \cdot$ John Haslett $^{3} \cdot$ Rob Tinch $^{4}$
}

Received: 21 November 2017 / Revised: 19 March 2018 / Accepted: 22 March 2018 /

Published online: 4 April 2018

(C) Springer Science+Business Media B.V., part of Springer Nature 2018

\begin{abstract}
This Editorial to the BESAFE special issue introduces the project and its approach and case studies. The BESAFE (EC 7th Framework programme) project investigated how the effectiveness of different types of arguments for biodiversity conservation depends on the context in which they are used. Our results show that tailoring of argumentation to audience within the course of decision processes is the main factor determining effectiveness. We consistently found arguments linked to intrinsic value (e.g. moral or ethical obligation arguments) as shared and supported widely, and thus offering common ground between parties. Economic arguments are effective as additional ones, but not as replacements. Next generation biodiversity conservation strategies can probably improve their effectiveness by emphasizing and better explaining the synergies between traditional conservation and especially regulating and cultural services.
\end{abstract}

Keywords Arguments for biodiversity conservation - Ecosystem services $\cdot$ Science policy interfaces

Communicated by David Hawksworth.

Rob Bugter

rob.bugter@wur.nl

1 Team Biodiversity and Policy, Wageningen Environmental Research (WENR), P.O. Box 47, 6700 AA Wageningen, The Netherlands

2 Centre for Ecology \& Hydrology (CEH), Lancaster Environment Centre, Library Avenue, Bailrigg, Lancaster LA1 4AP, UK

3 Department of Cell Biology and Physiology, Division of Animal Structure and Function, University of Salzburg, Hellbrunnerstrasse 34, 5020 Salzburg, Austria

4 Economics for the Environment Consultancy, 73-75 Mortimer Street, London W1W 7SQ, UK 


\section{Introduction}

Early arguments for biodiversity protection were focused on the conservation of charismatic and rare species, and this later broadened to include the preservation of habitats and spectacular landscapes through networks of protected areas, such as national parks (Haslett et al. 2010). The Millennium Ecosystem Assessment and other influential initiatives in the early 2000s triggered a major shift towards recognising the importance of ecosystems and their biodiversity in providing a wide range of services for humans. This "nature for people" framing sought to widen the range of arguments, and to "mainstream" conservation, attaching new importance to conserving nature outside protected areas and throughout all areas of human activity. At the same time, it created a context, and policy demand, for attempts to "value" the benefits of nature in economic terms and allow comparison with measures of economic activity (e.g. Bateman et al. 2013; Mace 2014).

This shift, and in particular the use of monetary valuations, has been contentious. There is concern that arguments driven by ecosystem services and their economic value have become too prevalent, and could endanger biodiversity conservation (e.g. Spash and Vatn 2006; Norgaard 2010; Rode et al. 2015). While economic arguments resonate strongly with some policy-makers, public support is often driven more by traditional nature conservation motives (EC 2013; Farjon et al. 2015). Most recently, a softer approach has started to emerge, with a greater focus on the resilience and adaptability of social-ecological systems, i.e. the interconnection of nature and people (Mace 2014).

Meanwhile, however, biodiversity has continued to decline. The question still remains: what arguments can convince society to take the actions necessary to stop biodiversity loss? Biodiversity protection depends on people and the decisions they take. Different individuals and institutions hold diverse values and priorities, and will be convinced to protect or reduce their impact on biodiversity by different arguments. Understanding how argumentation works, on what value judgements the various arguments are based, and why some arguments are accepted and others rejected in particular situations can be crucial for improving decision-making processes and making people more aware of why biodiversity needs to be protected.

In BESAFE, the project to which this special issue is dedicated, we investigated how different types of arguments for biodiversity protection generate effects, and how their effectiveness depends on when, where and how they are used, seeking to determine how the effectiveness of biodiversity argumentation can be improved.

\section{What is BESAFE}

BESAFE resulted from a call in the European Union's 7th framework programme expressing the concern that 'Endeavours to convince policy-makers to invest effort in vigorous action to conserve biodiversity depend increasingly on demonstrating the value of biodiversity to humans, largely through the concept of ecosystem services, to the extent that alternative arguments and strategies are sometimes neglected'. The call asked projects to assess the potential and observed effectiveness of the various arguments, to clarify the relationships between biodiversity and ecosystem services, and to analyse the implications of these relationships for the valuation of biodiversity (EC 2010). The BESAFE project explored the effectiveness of arguments for biodiversity protection in different contexts. 
The project involved 16 partners spread over 12 European countries and ran for 4 years, 2011-2015.

\section{BESAFE's approach}

The ultimate effectiveness of arguments for biodiversity protection in decision-making processes is difficult to observe due to significant time lags between the framing of argumentation and the final biodiversity outcomes. But successful arguments also have an immediate effect, measurable by how they are acknowledged and incorporated in subsequent steps of the decision-making process, and how they influence decisions there. We therefore chose to assess effectiveness by tracking arguments through the decision-making process by analysing process documentation and interviewing people involved (for implementation see Howard et al. 2013; Primmer et al. 2016; Jokinen et al. 2018; Tinch et al. 2018b).

We collected information to shape our analysis framework in three reviews. The first review covered linkages between ecosystem services and biodiversity (Harrison et al. 2014a) and was conducted to increase our knowledge on the relationship between biodiversity protection and ecosystem services. A second collected information on arguments in actual use in order to establish a workable typology (Howard et al. 2018). Finally, Primmer et al. (2015) considered governance literature and used the results to propose a framework providing a structure for the empirical analysis of ecosystem services governance.

\section{Case study research}

The BESAFE case studies were selected to cover the use of a wide array of different arguments over a range of different ecological, economic and social decision-making contexts, with a variety of governance levels, time scales, and policy cycle stages between them as well as within them. Case studies selected represented "real" problems involving a current controversy related to a biodiversity issue. To facilitate analysis of the argumentation process, cases had to be rich enough in records to enable the study of trade-offs and synergies as well as linkages/transmission between scales. Different stakeholder groups needed to be involved (e.g., public, policy, science, hunters) and case studies needed to cover cultural, political and institutional embeddedness of argumentation; and how stakeholders differ in their understanding of the relationship between biodiversity, ecosystem services and values (Blicharska and Jokinen 2012). Thirteen case studies were finally selected (Table 1).

Most of the case studies resulted in independent publications, five of which are part of this special issue (see Table 1). All case studies collated qualitative data which was analysed in terms of the effectiveness of arguments (Primmer et al. 2016), argumentation in multi-level governance interactions (Van Herzele 2014) and the relationship between biodiversity, ecosystem services and values (Harrison et al. 2014b).

In all the selected case studies the controversies in one way or another concerned a distinction or contrast between conservation and (economic) use. Four case studies investigated old and deep-rooted frictions between conservation and other interests: the Bialowieza forest conflict (Blicharska and Van Herzele (2015); return of the red fox and wild boar to Flanders (Van Herzele et al. 2015); conflict over the management of large carnivores and herbivores in Norwegian wildlands (Bredin et al. 2015); conflicting uses of peatlands in Finland (Albrecht and Ratamäki 2016). These cases provided information on (or changes in) the strategic and opportunistic use of arguments by stakeholders in the course 


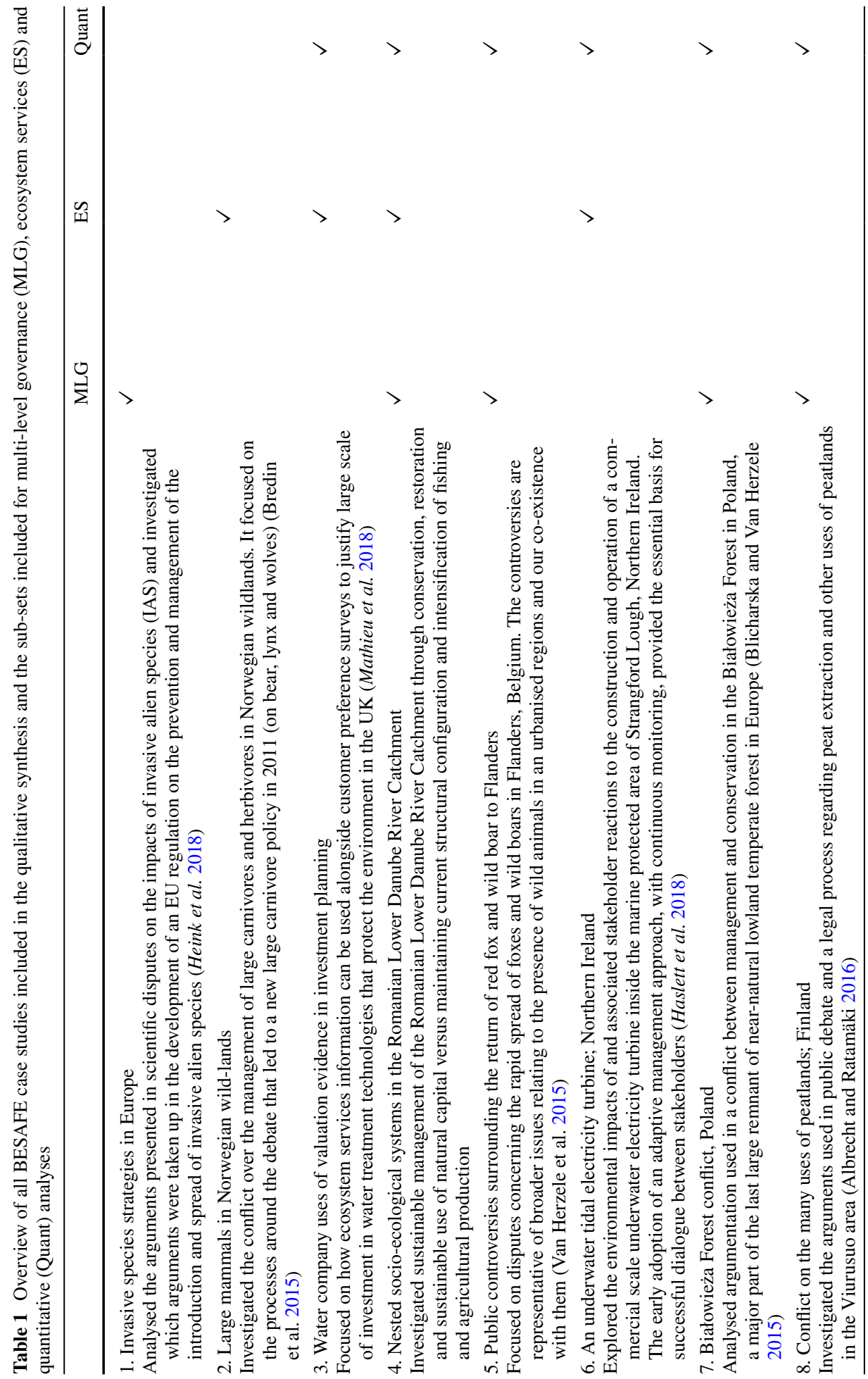




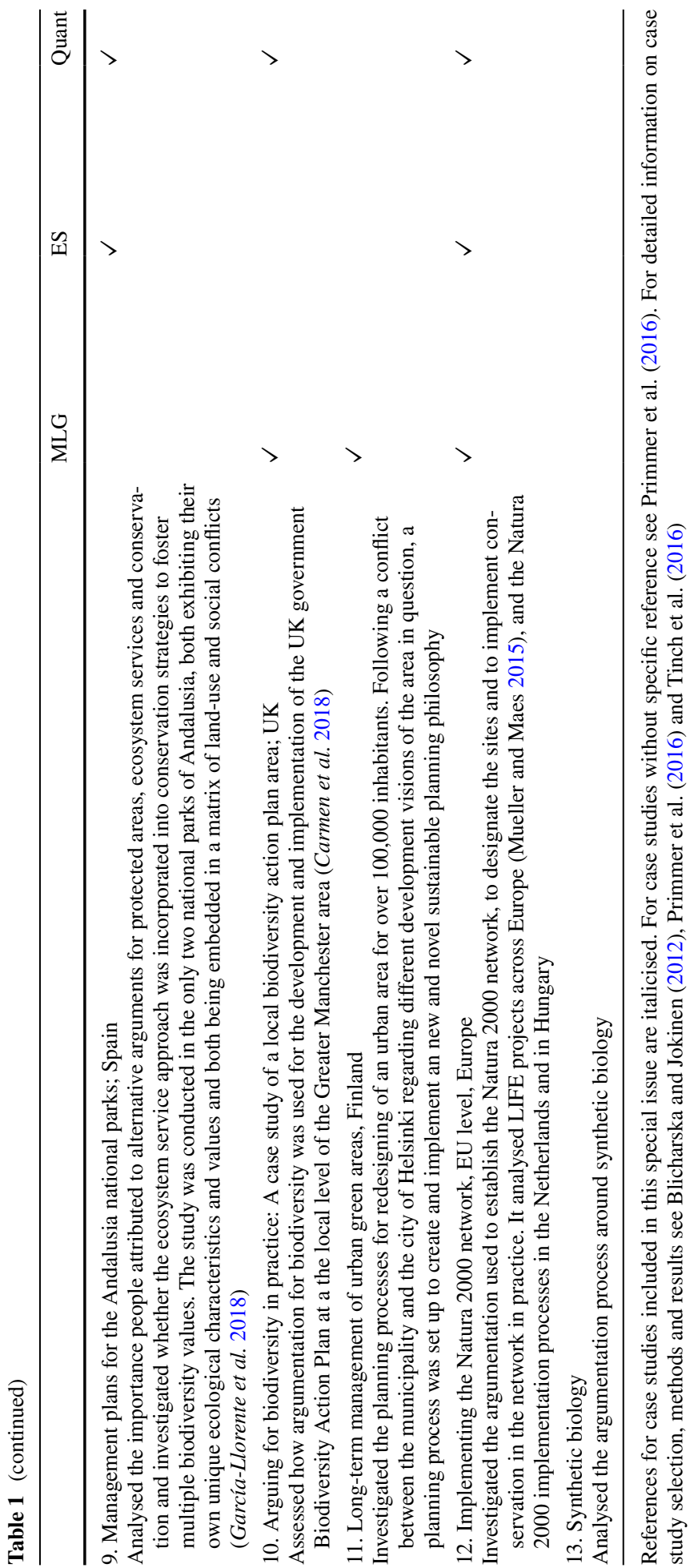


of the process, on how the debate itself can produce a polarising dynamic, and on common grounds for developing more constructive relationships between parties.

The case studies on management plans for the Andalusia national parks (García-Llorente et al. 2018), nested socio-ecological systems in Romania (see Primmer et al. 2016), and water company uses of valuation evidence in investment planning in the UK (Mathieu et al. 2018), provided information on how increased understanding had a clear influence on decision making.

The Finnish urban green areas case study (see Primmer et al. 2016) and the UK local biodiversity action plan case study (Carmen et al. 2018) provided additional information on situations where specific arguments were used at the policy level, but did not transfer to the implementation level due to a lack of awareness or common ground. These case studies also provided information on the effectiveness of a strong policy framework for the conservation of biodiversity in polarised situations where a bottom-up process does not work due to a lack of common ground.

Three case studies investigated relatively recent controversies in which the shift in thinking about (the balance between) conservation and use of (biodiversity) resources is evident: the synthetic biology case study explored the argumentation around the conflict between possible economic gains obtainable from artificial biological systems and the possible risks for biodiversity (see Primmer et al. 2016). In the invasive species case study (Heink et al. 2018), conservation and use values were combined in an adapted definition of invasive alien species: as species whose introduction or spread has not only been found to threaten biodiversity but also ecosystem services, and therefore may also have a negative impact on human health or the economy. In the marine turbine case study the process of assessing possible conflicts between the production of renewable energy and conservation targets was investigated and evolved under an adaptive management approach (Haslett et al. 2018).

The case study on the implementation of the Natura 2000 (N2000) network investigated the argumentation around LIFE projects targeting restoration activities in N2000 sites (Mueller and Maes 2015), and the investigation of argumentation around the N2000 implementation in The Netherlands and Hungary (see Primmer et al. 2016). The two national implementation studies offered insight into how EU policy percolates down and interacts with local interests, while the LIFE study contributed insight into stakeholder's interests and opinions and the role of ecosystem services arguments.

\section{Additional studies and synthesis}

Q-methodology is used to investigate the perspectives of participants by letting them rank and sort a series of statements (Webler et al. 2009). Two studies used this methodology to explore stakeholder interests and views in nine EU member states, in seven of which case studies were located (Berry et al. 2018; Primmer et al. 2017). The Norwegian case study (Bredin et al. 2015) also explored stakeholder views by means of a Q-study. Together with the N2000 LIFE study (Mueller and Maes 2015), these studies provided information on shared perspectives and common ground between stakeholders from different disciplines and walks of life.

Jokinen et al. (2018) investigated how biodiversity conservation argumentation generates effects in policy cycles in the two Finnish case studies, the Bialowieza case study, and the wildlife comeback case study in Flanders (Table 1). This provided insight into the way argumentation evolves over the course of the policy cycle, and the key role of framing across policy stages. 
In most of the case studies we also collected quantitative data on the effectiveness of arguments. These data were analysed and combined with the results of the qualitative analysis (Primmer et al. 2016) in Tinch et al. (2018b). This combined analysis clearly showed the importance of factors like bundling, framing and tailoring of arguments.

\section{Key findings}

\section{Argument types matter within contexts}

There is evidence from our case studies that the acceptance, and thus effectiveness, of new arguments, like the value of ecosystem services, depends on awareness. Improved transfer of knowledge from the scientific community to other stakeholders can for instance increase awareness of, and concern for, ecosystem services and the biodiversity that underpins them. In the Andalusian and Romanian case studies (Table 1), for example, local people were initially largely concerned with provisioning services such as fishing and farming, but the value they placed on cultural and regulating services increased following provision of better information. In the UK, a key policy-maker (the water regulator) also changed their approach following scientific demonstration of the benefits of catchment management to prevent water pollution (Mathieu et al. 2018). Other case studies, however, showed that (awareness of) ecosystem service values not always (yet) reaches or persists at local levels of governance (Van Herzele et al. 2014; Carmen et al. 2018; Albrecht and Ratamäki 2016). Moreover, ecosystem service arguments are only effective if there is common ground and mutual acceptance of ecosystem service values. In polarised situations where this is not the case, arguments with recognised (legal) status are more effective. This suggests that the facilitation of bottom up initiatives within a solid top down policy framework is most likely to provide the conditions for developing effective arguments for biodiversity.

Although many of the case studies identified links between types of arguments and actors (Blicharska and Van Herzele 2015; Van Herzele et al. 2015; Mueller and Maes 2015; Bredin et al. 2015), these links turned out to be case study specific. In the overall effectiveness synthesis (Tinch et al. 2018b) only legal arguments showed a slightly larger than average overall effectiveness, probably illustrating the value of a solid formal protection framework.

\section{Tailoring to audience determines effectiveness}

How an issue is framed in argumentation can significantly change what actors think about it (e.g. Callaghan and Schnell 2009; Miller et al. 2009; Rantala and Primmer 2003). Many of the case studies reported on (the effects of) different aspects of framing: e.g. positive or negative framing of issues and selecting arguments thought to matter to the receiver (Carmen et al. 2018), and strategic use of arguments (Van Herzele et al. 2015; Blicharska and Van Herzele 2015). Adapting the combination of arguments to changes in situation also frequently occurred, e.g. in the Andalusian (García-Llorente et al. 2018) and Romanian (see Primmer et al. 2016) case studies where stakeholders gradually became aware of the synergies between conservation and regulating and cultural services. Both national Natura 2000 implementation processes in Hungary and The Netherlands showed an adaptation of the arguments used from the national to the local level (see Primmer et al. 2016). As highlighted by Fairclough and Fairclough (2012), actors (as individuals as well as groups) may have a number of concerns 
and goals. Thus, linking and presenting bundles of positively framed arguments can increase the likelihood of a claim being accepted. This view is further supported by the results of Q-studies investigating stakeholder views (Bredin et al. 2015; Berry et al. 2018; Primmer et al. 2017), that all found different groups of stakeholders to have (varying degrees and aspects of) overlap in views.

Tailoring argumentation to the specific audience is therefore potentially a powerful instrument to increase effectiveness. However, tailoring of argumentation needs knowledge on the physical and organisational options as well as on the views and requirements of the parties in the decision-making process. Trust was identified as an important factor determining credibility of an arguer and consequently the effectiveness of the arguments he or she uses (Tinch et al. 2018b; Primmer et al. 2016). Effective argumentation is therefore to a large extent the result of a process with time for, and attention to, tailoring and trust building. These findings are supported by the results of the EU SPIRAL project presented in Tinch et al. (2018a), who emphasize the importance of the same factors for the development of an effective sciencepolicy interface.

That new insights result in new ways of arguing, with increased credibility and value for new arguments embedded in new narratives, is shown by Heink et al. (2018) for the argumentation around the invasive species policy, and especially by Rose et al. (2018) who present an example of very effective tailoring of a protection narrative in the UK.

\section{There is common ground to build on}

Although the Norwegian case study concerned an old and fairly entrenched discussion in which there has not been much change, the results identified possible common ground in the views of the stakeholders and therefore a possible way forward (Bredin et al. 2015). This common ground was also identified by Berry et al. (2018), who explored how different conservation practitioners (environmental non-governmental organisations, decision-makers, and social and natural science researchers) in nine European countries argue for conservation. They found a plurality of views about biodiversity and its conservation. The view that biodiversity conservation is a moral issue was however shared by all stakeholder groups, and some arguments around the intrinsic and ecological value of biodiversity were also accredited by all groups.

This study showed that many stakeholders from all walks of life attach considerable importance to the intrinsic value of nature, and place a high value on cultural and aesthetic ecosystem services. On the other hand, the expert stakeholders also rejected the concern that valuation of ecosystems is likely to provide a justification for their destruction. Primmer et al. (2017) who further analysed the views of the same decision-makers, found that although the personal motivations of these decision makers were at least partly 'intrinsic', the arguments they thought were needed/accepted in the policy arena were invariably completely instrumental.

These results imply that there is a role for several lines of argument supporting the protection of biodiversity: based on, for example, the right of species to exist, the value to humans, and the "insurance policy" approach. 


\section{Final conclusion}

Across the BESAFE project, we consistently found arguments linked to intrinsic value (e.g. moral or ethical obligation arguments) as shared and supported widely, and thus offering common ground between parties. The importance of intrinsic value as a ground for protection also shows in Eurobarometer surveys on attitudes towards biodiversity (EC 2013) and in a recent survey of citizens' images and values of nature in Europe in nine EU Member States (Farjon et al. 2015). Both surveys, apart from showing that people support conservation for various reasons, indicate that 'the responsibility we have to look after nature' and 'the intrinsic value of nature' are more strongly supported as arguments for protection than arguments emphasizing the benefits we get from biodiversity. Against this background, our results could in particular be used to justify a revaluing of ethical and moral arguments for biodiversity conservation, as it seems that many decision-makers and other stakeholders respond to those arguments.

The additional (economic) value of ecosystem services was a key consideration in both the Millennium Ecosystem Assessment (MEA 2005) and The Economics of Ecosystems and Biodiversity (TEEB 2010). But its emergence also rekindled an old conflict around why we conserve biodiversity. Tallis and Lubchenco (2014) observe this has led to a heated debate 'between in essence, those who argue that nature should be protected for its own sake (intrinsic value), and those who argue that we must also save nature to help ourselves (instrumental value)'. Our results imply that lines of argument based on different value types should have a joint role in supporting the protection of biodiversity. In accordance with Tallis and Lubchenko's call for all-inclusive conservation, we find that the key to improving biodiversity protection seems to be to ensure a better balance between these arguments and their wider dissemination to all stakeholder groups, rather than to push a regime based on a narrow value set which ignores, and therefore does not exploit, the existing general support for a much wider value range.

Our results indicate that there is some reason for concern about the possible negative effects of concentrating on a (too) narrow value base on the economic side of the spectrum. A key learning point is illustrated by the LIFE site manager opinions recorded by Mueller and Maes (2015). These managers, on the one hand, expressed concern that subsidising stakeholders for conservation actions might deter intrinsic motivation, while on the other hand none of them saw a risk of crowding out intrinsic motivations by economic arguments, as long as the intrinsic arguments continued to be used. In other words: economic arguments are useful as additional ones, but not as replacements. And when economic arguments are pushed too single-mindedly, concern is probably justified. This possible risk is further illustrated by the finding of Primmer et al. (2017) that biodiversity decision-makers, often in contrast to their personal believes, only cited instrumental arguments when asked which ones would be effective in the policy domain. As our results as well as Eurobarometer (EC 2013) and Farjon et al. (2015) indicate, implementation level support, and especially the support of people active in conservation (Dedeurwaerdere et al. 2016), is still mainly for 'intrinsic', traditional, conservation motives. If these motives are not properly valued in policy implementations, the risk that on the ground support erodes is imaginable.

Although a proper revaluation of our motives for recognising the value of nature and biodiversity for their own sake certainly seems to be necessary, a quicker and probably easier way to prevent the fading of intrinsic value arguments from the policy domain could be to emphasize the value of the link between traditional and new conservation 
in a next cycle of policy design and formulation. At the moment, the current European Union's Biodiversity Strategy to 2020 (EC 2011), for instance, indicates the protection of the biodiversity underlying services as a necessary additional, but spatial and implementation-wise separate effort. Although the possible spin-off of this extra effort for Natura 2000 targets is indicated in the strategy, the key role of Natura 2000 for long term sustainable delivery of especially supporting and regulating services is not. Clearly presenting and explaining how the preservation of (genetic) diversity and ecological functioning relies on the system of protected areas, habitats and species and why this is essential for the economics of biodiversity could well be decisive in avoiding unnecessary conflicts between seemingly competing interests in a next strategy.

Acknowledgements This research has received funding from the European Community's Seventh Framework Programme under BESAFE (EC-282743) project. Many people were involved in this study as researchers, stakeholders, workshop participants, interviewees, reviewers or otherwise. We are grateful to all of them for their contributions, without which this work would not have been possible.

\section{References}

Albrecht E, Ratamäki O (2016) Effective arguments for ecosystem services in biodiversity conservation-a case study on Finnish peatland conservation. Ecosyst Serv 22:41-50. https://doi. org/10.1016/j.ecoser.2016.09.003

Bateman IJ, Harwood AR, Mace GM, Watson RT, Abson DJ, Andrews B, Binner A, Crowe A, Day BH, Dugdale S, Fezzi C, Foden J, Hadley D, Haines-Young R, Hulme M, Kontoleon A, Lovett AA, Munday P, Pascual U, Paterson J, Perino G, Sen A, Siriwardena G, van Soest D, Termansen M (2013) Bringing ecosystem services into economic decision-making: land use in the United Kingdom. Science 341:45-50

Berry PM, Fabók V, Blicharska M et al (2018) Why conserve biodiversity? A multi-national exploration of stakeholders' views on the arguments for biodiversity conservation. Biodivers Conserv. https:// doi.org/10.1007/s10531-016-1173-z

Blicharska M, Jokinen P (2012) Report on the selection of case studies. BESAFE deliverable D2.1. http://www.besafe-project.net/deliverables.php? $\mathrm{P}=4 \& \mathrm{SP}=32$

Blicharska M, Van Herzele A (2015) What a forest? Whose forest? Struggles over concepts and meanings in the debate about the conservation of the Białowieża Forest in Poland. Forest Policy Econ 57:22-30

Bredin YK, Lindhjem H, van Dijk J, Linnell JDC (2015) Mapping value plurality towards ecosystem services in the case of Norwegian wildlife management: a Q analysis. Ecol Econ 118:198-206. https:// doi.org/10.1016/j.ecolecon.2015.07.005

Callaghan K, Schnell F (2009) Who says what to whom: why messengers and citizen beliefs matter in social policy framing. Soc Sci J 46(1):12-28

Carmen E, Young J, Watt A (2018) Arguing for biodiversity in practice. Biodivers Conserv. https://doi. org/10.1007/s10531-016-1264-X

Dedeurwaerdere $\mathrm{T}$ et al (2016) Combining internal and external motivations in multi-actor governance arrangements for biodiversity and ecosystem services. Environ Sci Policy 58:1-10. https://doi. org/10.1016/j.envsci.2015.12.003

EC (European Commission) (2010) Work programme 2011 cooperation theme 6 environment (including climate change). European Commission C(2010) 4900 of 19 July 2010

EC (European Commission) (2011) Our life insurance, our natural capital: an EU biodiversity strategy to 2020. COM(2011) 244, Brussels

EC (European Commission) (2013) Flash Eurobarometer 379: attitudes towards biodiversity. http://ec.europ a.eu/environment/eurobarometers_en.htm

Fairclough I, Fairclough N (2012) Political discourse analysis: a method for advanced students. Routledge, Abingdon 
Farjon H, de Blaeij A, de Boer T, Langers F, Vader J, Buijs A (2015) Citizens' images and values of nature in Europe. A survey in nine EU Member States. PBL publication number: 1662, PBL Netherlands Environmental Assessment Agency, The Hague

García-Llorente M, Harrison PA, Berry P et al (2018) What can conservation strategies learn from the ecosystem services approach? Insights from ecosystem assessments in two Spanish protected areas. Biodivers Conserv. https://doi.org/10.1007/s10531-016-1152-4

Harrison PA, Termansen M, Smith AC (2014a) Final report on relationships between biodiversity, ecosystem services and values in case studies: BESAFE deliverable 4.1, synthesis. http://www.besaf e-project.net/deliverables.php?P=4\&SP=32

Harrison PA et al (2014b) Linkages between biodiversity attributes and ecosystem services: a systematic review. Ecosyst Serv 9:191-203. https://doi.org/10.1016/j.ecoser.2014.05.006

Haslett JR, Berry PM, Bela G, Jongman RHG, Pataki G, Samways MJ, Zobel M (2010) Changing conservation strategies in Europe: a framework integrating ecosystem services and dynamics. Biodivers Conserv 19(10):2963-2977. https://doi.org/10.1007/s10531-009-9743-y

Haslett JR, Garcia-Llorente M, Harrison PA et al (2018) Offshore renewable energy and nature conservation: the case of marine tidal turbines in Northern Ireland. Biodivers Conserv. https://doi. org/10.1007/s10531-016-1268-6

Heink U, Van Herzele A, Bela G et al (2018) Different arguments, same conclusions: how is action against invasive alien species justified in the context of European policy? Biodivers Conserv. https ://doi.org/10.1007/s10531-016-1170-2

Howard BM, Braat L, Bugter R, Young JC, Hails RH (2013) Report on the classification of arguments and the provisional framework. BESAFE deliverable D1.1. http://www.besafe-project.net/deliv erables.php? $\mathrm{P}=4 \& \mathrm{SP}=32$

Howard B, Braat LC, Bugter RJF et al (2018) Taking stock of the spectrum of arguments for biodiversity. Biodivers Conserv. https://doi.org/10.1007/s10531-016-1082-1

Jokinen P, Blicharska M, Primmer E, Van Herzele A, Kopperoinen L, Ratamäki O (2018) How does biodiversity conservation argumentation generate effects in policy cycles? Biodivers Conserv. https ://doi.org/10.1007/s10531-016-1216-5

Mace GM (2014) Whose conservation? Science 345:1558-1560. https://doi.org/10.1126/science.12547 04

Mathieu L, Tinch R, Provins A (2018) Catchment management in England and Wales: the role of arguments for ecosystems and their services. Biodivers Conserv. https://doi.org/10.1007/s10531-016-1176-9

MEA (2005) Millennium ecosystem assessment: ecosystems and human well-being: synthesis. Island Press, Washington, DC

Miller P, Fagley N, Casella N (2009) Effects of problem frame and gender on principals' decision making. Soc Psychol Educ 12:397-413

Mueller A, Maes J (2015) Arguments for biodiversity conservation in Natura 2000 sites: an analysis based on LIFE projects. Nature Conserv 12:1-26

Norgaard RB (2010) Ecosystem services: from eye-opening metaphor to complexity blinder. Ecol Econ 69(6):1219-1227

Primmer E, Jokinen P, Blicharska M, Barton DN, Bugter R, Potschin M (2015) Governance of ecosystem services: a framework for empirical analysis. J Ecosystem Serv 16:158-166. https://doi. org/10.1016/j.ecoser.2015.05.002

Primmer E, Jokinen P, Blicharska M (2016) Final report synthesizing the analysis on effectiveness in case studies. BESAFE Deliverable 2.3. http://www.besafe-project.net/deliverables.php?P=4\&SP=32

Primmer E, Termansen M, Bredin YK, Blicharska M, Garcia-Llorente M, Berry P, Jääskeläinen T, Bela G, Fabók V, Geamana N, Harrison PA, Haslett J, Cosor G, Holst Andersen A (2017) Caught between personal and collective values: biodiversity conservation in European decision-making. Environ Policy Gov 27(6):588-604. https://doi.org/10.1002/eet.1763

Rantala T, Primmer E (2003) Value positions based on forest policy stakeholders' rhetoric in Finland. Environ Sci Policy 6(3):205-216

Rode J, Gomez-Baggethun E, Krause T (2015) Motivation crowding by economic incentives in conservation policy: a review of the empirical evidence. Rev Ecol Econ 117:270-282

Rose DC, Brotherton PNM, Owens S, Pryke T (2018) Honest advocacy for nature: presenting a persuasive narrative for conservation. Biodivers Conserv. https://doi.org/10.1007/s10531-016-1163-1

Spash CL, Vatn A (2006) Transferring environmental value estimates: issues and alternatives. Ecol Econ 60(2):379-388

Tallis H, Lubchenco J (2014) Working together: a call for inclusive conservation. Nature 515(7525):27-28

TEEB (2010) The economics of ecosystems and biodiversity: mainstreaming the economics of nature: a synthesis of the approach, conclusions and recommendations of TEEB 
Tinch R, Mathieu L, Haslett J (2016) Synthesis report on the revised and tested framework, the toolkit and accompanying policy brief. BESAFE Deliverable 5.2. http://www.besafe-project.net/deliverabl es.php?P=4\&SP=32

Tinch R, Balian E, Carss D et al (2018a) Science-policy interfaces for biodiversity: dynamic learning environments for successful impact. Biodivers Conserv. https://doi.org/10.1007/s10531-016-1155-1

Tinch R, Bugter R, Blicharska M, Harrison P, Haslett J, Jokinen J, Mathieu L, Primmer E (2018b) Arguments for biodiversity conservation: factors influencing their observed effectiveness in European case studies. Biodivers Conserv (in press)

Van Herzele A et al (2014) Final report synthesising the analysis of argumentation in multi-level governance interactions in case studies. BESAFE deliverable 3.1. http://www.besafe-project.net/deliverabl es.php?P=4\&SP=32

Van Herzele A, Aarts N, Casaer J (2015) Wildlife comeback in Flanders: tracing the fault lines and dynamics of public debate. Eur J Wildl Res 61:539-555. https://doi.org/10.1007/s10344-015-0925-5

Webler T, Danielson S, Tuler S (2009) Using Q method to reveal social perspectives in environmental research. Social and Environmental Research Institute, Greenfield, MA 